\title{
Economic Impact of the Recent Decrease in Social Security Contributions in Ukraine
}

\author{
Philipp Engler \\ Free University Berlin \\ Robert Kirchner \\ German Advisory Group
}

\author{
Simon Voigts \\ Humboldt University Berlin \\ Oleksandra Betliy \\ Institute for Economic Research and Policy Consulting
}

\begin{abstract}
Social security contributions paid by firms were massively reduced in January 2016. We employ a state-of-the-art DSGE model to assess the effects of this measure on output, private consumption, and other key macroeconomic variables. We find that it significantly boosts GDP and consumption while reducing inflation, and that these effects are sizable both in the shortterm and in the long-term. We also report that the short-term impact is significantly stronger under an inflation targeting regime than under exchange rate stabilization.
\end{abstract}

\section{JEL Code: E62}

Keywords: fiscal devaluation, social security contributions

\section{INTRODUCTION}

At the beginning of 2016, as part of its reform of the tax code, Ukraine significantly reduced the social security contribution (SSC) paid by firms. Ukraine is in good company here, as similar reforms have been undertaken by many European countries in the past. The payroll tax rate was massively reduced from an average of $44 \%$ to $22 \%$. The idea behind this reform is to reduce labor costs so that firms become more competitive, thus boosting exports, investment, and real wages. This poses the question of what the economic implications of this reform will be in Ukraine. In this article, we present the results of our projections using a state-of-the-art economic model.

For our analysis, we employ a New Keynesian Dynamic Stochastic Equilibrium Model (DSGE), i. e. a mainstream macroeconomic model, which has been specifically tailored for analyzing the macroeconomic effects of a reduction in the payroll tax rate. Models of this class are quite good in capturing the short- to medium-term dynamics of the most important aggregate variables, but less so for long-term growth dynamics.

The massive reduction in the social security contribution will lead to significant revenue losses (up to UAH 100 billion, or more that 4\% of 2016E GDP, see the Dragon Capital Report Ukrainian Economy: Tax Changes and 2016 Budget: An Eminent Step Forward of 11 January 2016), which will be only partially compensated for by revenue-increasing measures (e.g., the salary cap on which SSC applies was increased). We assume that a resulting revenue shortfall of $3 \%$ of GDP is fully offset by a corresponding reduction in government spending to keep the deficit unchanged. We use the model to simulate the impact of the cut in the SSC rate under three scenarios that differ with regard to the monetary policy stance of the National Bank of Ukraine (NBU). In the first scenario of strict inflation targeting, the cut in social security contributions leads to a steep depreciation of the exchange rate and boosts output by roughly $3.3 \%$ on impact. If the NBU stabilizes the nominal exchange rate - the second monetary policy stance under consideration - the induced expansion is considerably milder: the output increase is gradual and reaches its peak of about $0.6 \%$ after one year. A third scenario considers an intermediate case. The crucial role of monetary policy for the impact of tax reform is a central finding of our analysis.

Section 2 of this article provides an overview of the model, and Section 3 discusses the simulation results. Section 4 concludes our findings. 


\section{MODEL DESCRIPTION}

This article employs a model presented in detail in Engler et al. (2014). It is a model of the New Keynesian Dynamic Stochastic General Equilibrium (DSGE) class comprising two economies (Ukraine and the rest of the world) that trade goods and bonds with one another. We deviate from that model in that we assume the exchange rate to be flexible between the two countries. It is governed by the uncovered interest rate parity condition. The two economies' central banks influence their respective economies by changing the nominal interest rate, which affects real rates of interest (because prices react slowly to any kind of shock), which then in turn affect the savings and consumption decisions of households. Furthermore, terms of trade are affected by monetary policy via its impact on prices and via its impact on the nominal exchange rate. Changes in the terms of trade bring about consumption-switching effects between goods produced in the two economies. ${ }^{1}$

This article considers three different monetary policy regimes. In the first, the NBU aims at stabilizing domestic inflation, but has a neutral stance towards fluctuations in the nominal exchange rate. The second policy regime represents the opposite case, in which the central bank is only interested in stabilizing the exchange rate. The third regime is an intermediate case, in which both aims are weighted.

There are two types of households in the model that we must consider in order to understand how monetary policy affects inflation. ${ }^{2}$ The first type of households are "capitalists" who own the firms in their respective economy and are able to make explicit consumption and savings decisions that depend on a) their wealth and b) the real rate of interest. An increase in wealth results in an increase in consumption. A reduction in the real rate of interest incurs a reduction in savings and an increase in consumption. This increase in consumption increases aggregate demand for goods so that firms, who are assumed to use labor as their only input to production, need to adjust their labor input to serve that additional demand. The firms need to pay higher wages to be able to increase hours worked, which drives up their marginal costs so that they increase their prices therefore driving up the rate of inflation. This is the basic transmission mechanism through which a central bank affects the business cycle and inflation when they reduce the real rate of interest.

The second type of households are "hand-to-mouth" consumers who do not save at all but immediately use all of their income for consumption. Because in the scenario just described the real wage and hours rise, their consumption rises too, giving an additional boost to aggregate demand.

As domestic and foreign firms produce differentiated goods, any change in relative prices affects the relative demand for those goods. For example, when domestically produced goods become relatively cheaper than imported goods (i.e., the domestic terms of trade deteriorate), domestic and foreign consumers switch demand away from foreign goods and towards domestic goods. A central bank can deteriorate the terms of trade when it reduces the interest rate because this incurs a depreciation of the nominal exchange rate.

In the steady state of the model, the government levies taxes to pay for expenditures worth 37 percent of the gross domestic product. As common in the literature, government expenditures are defined as plain waste and, unlike private consumption, only consists of domestic goods. Revenue is generated through a payroll tax on wages which is paid by firms, a value added tax, income taxes, and a payroll tax paid by households. Any revenue the government does not need is returned to households in the form of lump-sum transfers.

Table 1 in the appendix depicts the calibration of the model. ${ }^{3}$

\section{SIMULATION RESULTS}

On 1 January 2016, the Ukrainian payroll tax rate was reduced from an average value of $44 \%$ to $22 \%$. As the payroll tax base was broadened, it is not exactly clear to what extent firms' effective payroll tax rate was reduced. We therefore assume that the payroll tax revenue was reduced by $3 \%$ of GDP. In our experiment, we assume that this is fully financed by a reduction in government spending. ${ }^{4}$

\footnotetext{
${ }^{1}$ The model does not account for the impact of exchange rate adjustments on firms' balance sheets. Balance sheet effects are potentially important and worth additional research. However, accounting for the latter in a DSGE framework would go beyond the scope of this analysis.

${ }^{2}$ We abstract from firms' capital accumulation, which is also instrumental in determining the effects of monetary policy on the real economy. However, the basic insights do not change much when we concentrate on consumption decisions.

${ }^{3}$ One key parameter for the effect of the reform is the substitution elasticity between domestic and foreign goods, since it governs the strength of consumption switching effects. The literature does not provide clear guidance on its size, with estimates ranging from 1 to 3 . We choose a value of 1.2, which is at the lower end of empirical estimates and below the value used in Engler et al. (2014). We use a small value for the sake of a conservative modelling approach. A higher substitution elasticity would boost the effect of the fiscal reform under consideration, so the presented results can be interpreted as a lower bound.

${ }^{4}$ This reduction in government expenditures is not to be understood as a reduction in the size of government. As we assume spending to be wasteful, i.e., not adding to households' well-being or serving as an input to production, our assumption can be understood as an increase in the efficiency of aggregate spending.
} 
Note that the government also abolished a $3 \%$ social security contributions rate paid by households, and introduced a general income tax rate of $18 \%$ (instead of levying $15 \%$ or $20 \%$ depending on the income). Both changes affect household income in opposite directions: The reduction in social security contributions increases disposable household income, while the unified income tax rate effectively works like a tax hike because most households initially paid $15 \%$. Since the net effect of both changes is not certain - but can be expected to be small, as both changes work against each other - we exclude these two tax adjustments in our experiment.

This fiscal policy is analyzed under the three different monetary policy regimes introduced in the previous section.

\subsection{Inflation targeting}

Figure 1 shows the impact of the fiscal policy reform under strict inflation targeting. Horizontal axes denote quarters after the implementation of the policy. Immediately after the payroll tax reduction and the government spending reduction, output and consumption increase by $3.3 \%$ and $2.1 \%$ respectively, and the trade balance relative to GDP improves by $1.6 \%$. The nominal exchange rate depreciates by about $5.9 \%$ and the GDP deflator falls by $2.4 \%$. The nominal interest rate declines by 3.4 percentage points. In the figure, one can see that the necessary reduction in government spending to render the payroll tax reduction budget neutral is about $2.4 \%$ of GDP. After several quarters, the rate of inflation and the nominal interest rate return to the long-term values and thereby the supporting effects of central bank action fades. However, output remains elevated by about $0.5 \%$ and consumption by $1.4 \%{ }^{5}$ The net asset position relative to GDP increased permanently by about $1.3 \%$.

\section{Figure 1. Impact of the fiscal policy under inflation targeting}

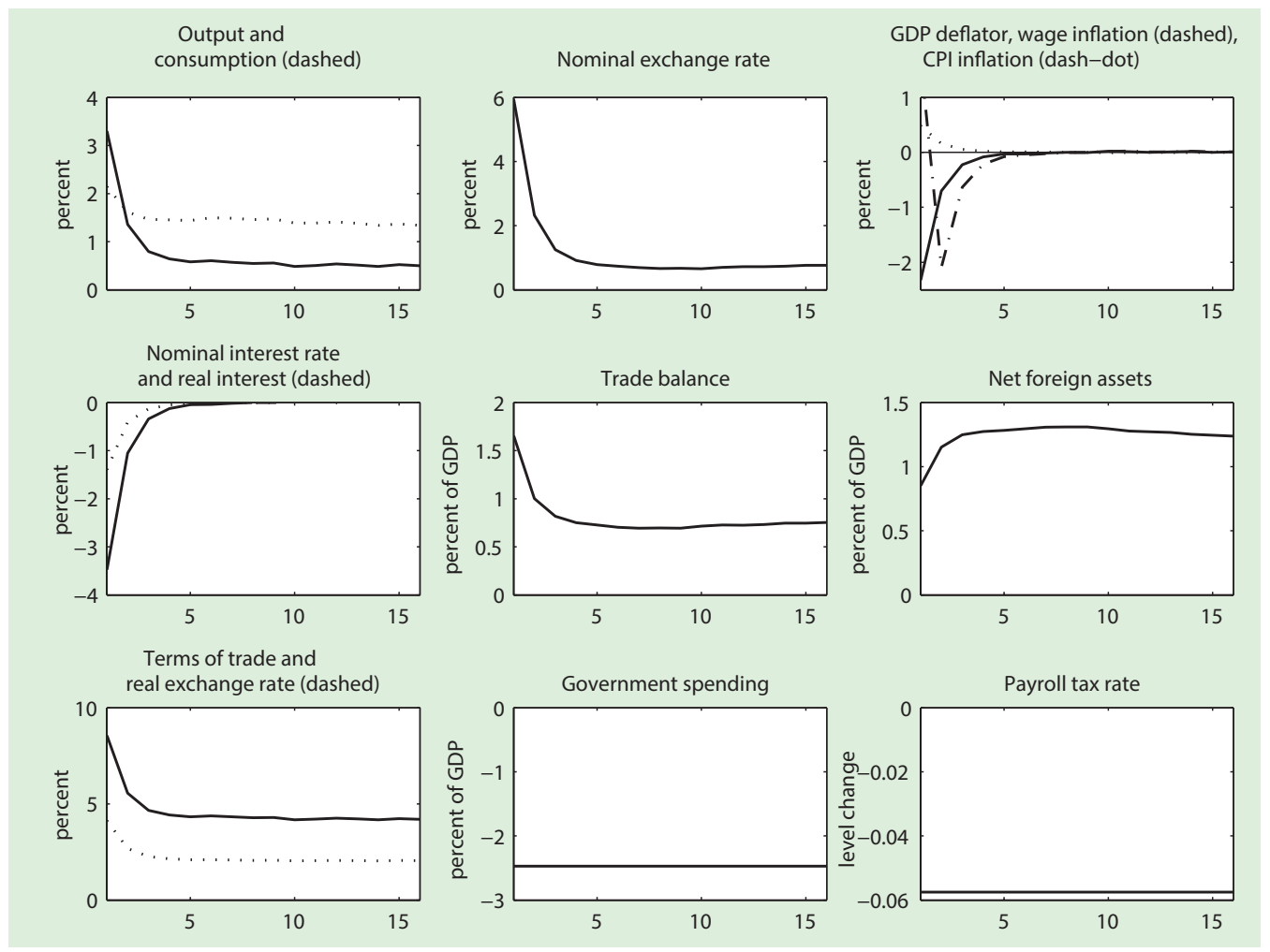

In the model, the payroll tax reduction reduces firms' production costs, which induces them to reduce prices to the extent that they face price competition, therefore incurring a fall in aggregate prices. Please note that this constitutes a fall in inflation below the average inflation rate of zero which we assume in the model, but which is clearly below the inflation rates observed in Ukraine. However, our results can be interpreted as a fall below the rate of inflation observed in the absence of the tax cut.

${ }^{5}$ As discussed in the conclusion, the model is designed to project short-term macroeconomic fluctuations, but not for a long-term analysis of the tax reform. The result of elevated long-term consumption is in a way trivial, since wasteful government consumption is permanently reduced, in line with permanently lower taxes. 
The tax cut implies an increase in Ukrainian firms' profits and a rise in real wages so that "capitalists" and "hand-to-mouth" consumers increase consumption and thereby boost aggregate demand for domestically produced goods. Furthermore, the deflationary pressure implies a reduction in the nominal and the real rate of interest (due to the central bank's reaction), which causes the nominal exchange rate to depreciate.

This lower real rate encourages consumption, while lower prices and the depreciated exchange rate cause a switching away from foreign towards domestic goods. Aggregate output and the trade balance thus rise. The additional demand for labor incurs an increase in the real wage so that hand-to-mouth households can increase consumption too. This increase in labor costs partially reverses the fall in firms' costs and aggregate prices fall somewhat less.

The reduction in government spending causes its own dynamics. Ceteris paribus, it reduces aggregate demand, the demand for labor, marginal costs, prices, and the real wage. A central bank reacts by reducing the nominal rate enough to reduce the real rate, which boosts private consumption, thereby partially replacing government spending (referred to as "crowding-in"). Because crowding-in is partial, aggregate demand is lower due to the spending cuts so that the net effect on prices is negative. Furthermore, the reduction of the interest rate depreciates the nominal exchange rate. Taken together, the price reduction and the fall in the currency's value depreciate the terms of trade and incur an expenditure switching away from foreign and towards domestic goods so that the trade balance improves.

Figure 2 provides a stylized overview of the impact of the fiscal reform.

\section{Figure 2. Stylized effect of fiscal policy}

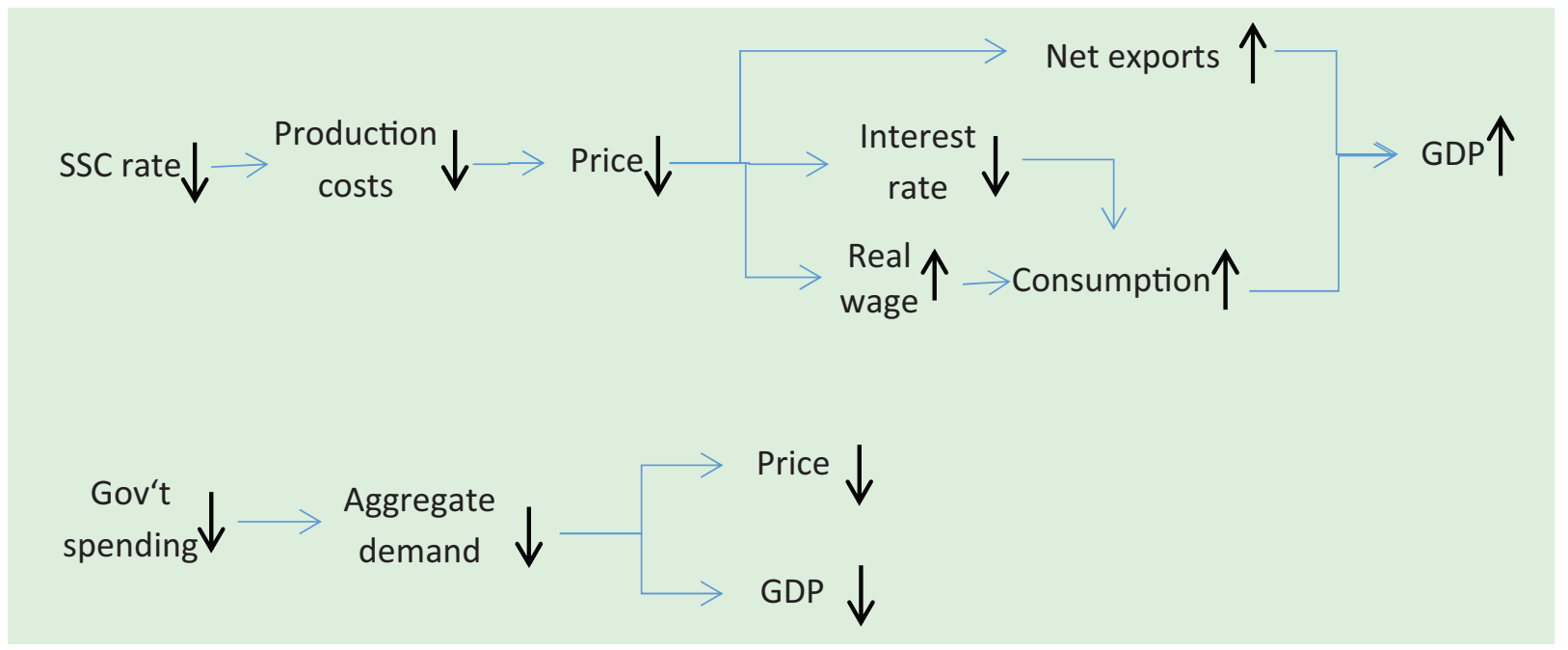

\subsection{Exchange rate stabilization}

Figure 3 shows the impact of the fiscal reform when a central bank stabilizes the nominal exchange rate (black lines). To facilitate comparison with the adjustment under the previous monetary policy regime of strict inflation targeting, blue lines replicate the adjustment shown in Figure 1. We observe that output and consumption drop slightly when the reform sets in. However, this drop is only short-lived as both variables gradually increase until differences between the adjustments under both monetary policy regimes have vanished after roughly four quarters. At that time, all firms adjusted prices in response to the tax cut, so there is no more deflationary pressure and the nominal interest rate under inflation targeting reverts to its longterm level. This means that the nominal interest rate is not different from its value under exchange rate stabilization, in which it never deviated from the long-term level. This explains why the impact of the fiscal reform is the same in both monetary policy regimes after roughly 5 quarters: monetary policy actions are in line, and the fiscal reform is the same. 
Figure 3. Impact of the fiscal policy under exchange rate stabilization
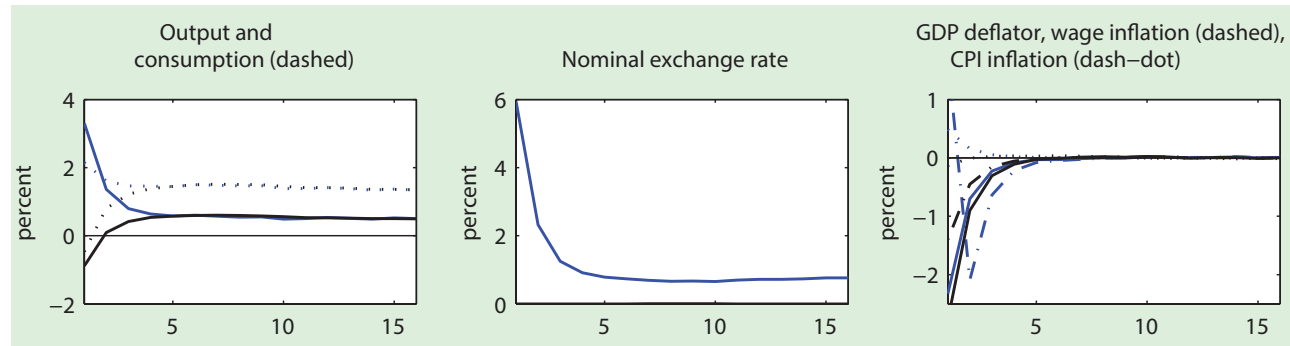

Nominal interest rate

and real interest (dashed)
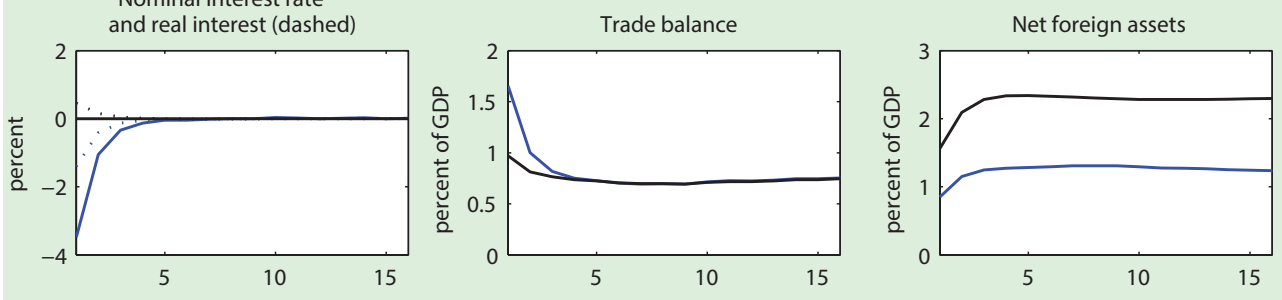

Terms of trade and

real exchange rate (dashed)
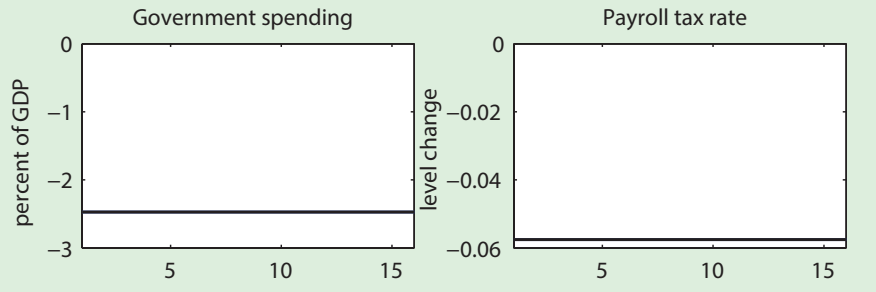

Stabilizing the nominal exchange rate requires keeping the nominal interest rate constant at the level of the foreign interest rate. The reason is that interest differentials would cause adjustments in the nominal exchange rate, since the latter is governed by the uncovered interest rate parity condition. The constant nominal interest rate has two implications that both reduce output relative to the scenario of inflation targeting. First, the real rate mildly deviates positively in the year after the implementation of the tax cut, because prices decline while the nominal rate is constant. This leads, ceteris paribus, to a reduction in household consumption in the short-term. Second, since there is no exchange rate depreciation, the deterioration in terms of trade is weaker than in the case of inflation targeting. This in turn leads to weaker expenditure switching, and mitigates the expansionary effect on output in the short-term.

It is surprising that the decline in prices is only slightly stronger than under inflation targeting: the GDP deflator declines by $2.3 \%$ under inflation targeting, and by $2.7 \%$ under exchange rate stabilization. The reason is that pricing decisions are based on a forward-looking calculus under Calvo-type price rigidity, while the differences between the adjustment under both monetary policy regimes is short-lived and fades out after roughly one year.

From a general point of view, expansionary monetary policy - which a central bank embarks on under inflation targeting in response to declining prices - is not feasible under exchange rate stabilization. As a result, a stimulating monetary policy impulse is absent, and the increase in aggregate demand exclusively stems from the deterioration of the terms of trade and the resulting expenditure switching effects.

\subsection{Intermediate monetary policy}

Figure 4 shows the impact of the fiscal reform when monetary policy follows an intermediate regime, i.e., puts equal weights on the stabilization of domestic prices and the foreign exchange rate. To allow a comparison with the inflation targeting regime, the model adjustment in the latter case is again depicted in blue lines. 


\section{Figure 4. Impact of the fiscal policy under mixed monetary policy}

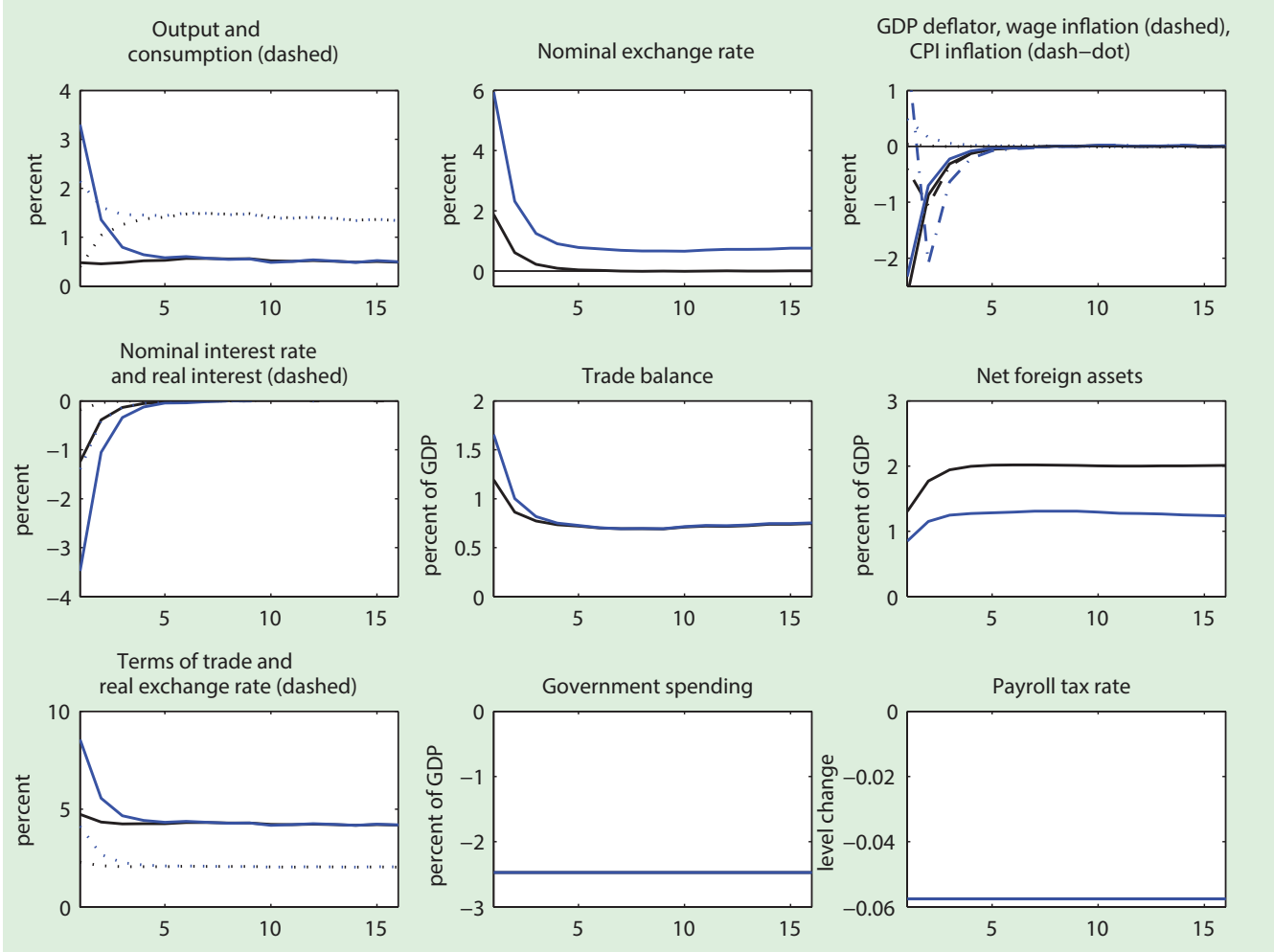

We observe that the strength of the immediate expansion in output and consumption lies in the middle of the two previously considered policy regimes: output and consumption increase on impact by about $0.5 \%$. This result is not surprising, given that a central bank conducts mild expansionary policy - weaker than under pure inflation targeting - in response to a decline in prices. The comparable modest reduction in the nominal interest rate (it declines by $1.2 \%$ on impact, as opposed to $3.4 \%$ under inflation targeting) leads to muted depreciation of the nominal exchange rate: the latter depreciates by $1.8 \%$, which is roughly half as much as under inflation targeting.

\section{CONCLUSION}

Our analysis, which should not be confused with a forecast, shows that there are a number of likely economic benefits associated with the recent cut in the payroll tax rate. While the model is not able to capture all the specifics of Ukraine's economy in full detail, it generally lends support to a reform that targets the high burden of labor taxation in Ukraine. In particular, we find that under inflation targeting, the reduction in payroll taxation leads to a sizable expansion in the short-term. Under exchange rate stabilization, when the NBU does not accommodate the measure with expansionary monetary policy, the short-term impact is considerably weaker. However, in both scenarios, the model predicts a significant increase in output in the mediumterm and long-term.

A note of caution is needed: The model we employ is well suited to model short- and medium-term dynamics, but it is not designed to model long-term growth dynamics. For that reason, the long-term effects should be taken with caution. However, as it is quite plausible that a reduction of wasteful government activity and distortionary taxes is able to boost private enterprise, our long-term results for output and private consumption are likely to underestimate the true effects.

\section{References}

- Engler P., Voights S., Kirchner R., Betliy O. (2016). Economic impact of the recent decrease in social security contributions. A model based analysis. German Advisory Group Policy Brief, Series No. 09-2016.

- Engler P., Ganelli G., Tervela J., Voights S. (2014). Fiscal Devaluation in a Monetary Union. Working Paper, Vol. 14, No. 201, IMF. https://doi.org/10.5089/9781484312131.001 


\section{Appendix}

Table 1. Parametrization of the model

\begin{tabular}{l} 
Size Ukraine \\
Size rest of the world \\
Share hand-to-mouth consumers \\
Substitution elasticity between domestic and foreign goods \\
(also for rest of the world) \\
Discount factor \\
Intertemporal elasticity of substitutions \\
Labor supply elasticity \\
Elasticity of subst. between Ukrainian goods \\
Elasticity of subst. between labor types \\
\hline Prices are re-set on average \\
\hline Wages are re-set on average \\
\hline Consumption tax rate \\
\hline Firms' payroll tax rate \\
\hline Households' payroll tax rate \\
\hline Households' income tax rate
\end{tabular}

\begin{tabular}{|c|}
\hline 0.01 \\
\hline 0.99 \\
\hline 0.7 \\
\hline 1.2 \\
\hline 0.99 \\
\hline 1 \\
\hline 1 \\
\hline 9 \\
\hline 9 \\
\hline every two quarters \\
\hline every two quarters \\
\hline 0.2 \\
\hline 0.44 \\
\hline 0.03 \\
\hline 0.15 \\
\hline
\end{tabular}

